Article

\title{
Heart Failure Patients' Adherence to Hybrid Comprehensive Telerehabilitation and Its Impact on Prognosis Based on Data from TELEREH-HF Randomized Clinical Trial
}

\author{
Ewa Piotrowicz $^{1, *}$, Michael Pencina ${ }^{2}$, Grzegorz Opolski ${ }^{3}$, Wojciech Zaręba ${ }^{4}$, Maciej Banach ${ }^{5}$, Ilona Kowalik ${ }^{6}{ }^{1}$, \\ Piotr Orzechowski ${ }^{1}{ }^{(D)}$, Renata Główczyńska ${ }^{3}$, Dominika Szalewska ${ }^{7}$, Sławomir Pluta ${ }^{8}$, Zbigniew Kalarus ${ }^{8}$, \\ Robert Irzmański ${ }^{9}$ and Ryszard Piotrowicz ${ }^{6,10}$
}

Citation: Piotrowicz, E.; Pencina, M.; Opolski, G.; Zaręba, W.; Banach, M.;

Kowalik, I.; Orzechowski, P.;

Główczyńska, R.; Szalewska, D.; Pluta, S.; et al. Heart Failure Patients' Adherence to Hybrid Comprehensive Telerehabilitation and Its Impact on Prognosis Based on Data from TELEREH-HF Randomized Clinical Trial. Appl. Sci. 2022, 12, 2595. https://doi.org/10.3390/app12052595 Academic Editor: Fernando Ribeiro

Received: 13 January 2022 Accepted: 28 February 2022 Published: 2 March 2022

Publisher's Note: MDPI stays neutral with regard to jurisdictional claims in published maps and institutional affiliations.

Copyright: (C) 2022 by the authors. Licensee MDPI, Basel, Switzerland. This article is an open access article distributed under the terms and conditions of the Creative Commons Attribution (CC BY) license (https:// creativecommons.org/licenses/by/ $4.0 /)$.
1 Telecardiology Center, National Institute of Cardiology, 04-628 Warsaw, Poland; porzechowski@ikard.pl

2 Duke University's School of Medicine, Durham, NC 27710, USA; michal.pencina@duke.edu

3 1st Chair and Department of Cardiology, Medical University of Warsaw, 02-091 Warsaw, Poland; grzegorz.opolski@wum.edu.pl (G.O.); reniarenata@gmail.com (R.G.)

4 University of Rochester Medical Center, Rochester, NY 14642, USA; wojciech_zareba@urmc.rochester.edu

5 Department of Hypertension, Medical University of Łódź, 90-419 Łódź, Poland; maciej.banach@icloud.com

6 National Institute of Cardiology, 04-628 Warsaw, Poland; ikowalik@ikard.pl (I.K.); rpiotrowicz@ikard.pl (R.P.)

7 Department of Rehabilitation Medicine, Medical University of Gdańsk, 80-210 Gdańsk, Poland; dominika.szalewska@gumed.edu.pl

8 Department of Cardiology, Congenital Heart Diseases and Electrotherapy, Silesian Center for Heart Diseases, Silesian Medical University, 41-800 Zabrze, Poland; spluta77@gmail.com (S.P.);

zbigniewkalarus@kalmet.com.pl (Z.K.)

9 Department of Internal Medicin and Cardiac Rehabilitation, Medical University of Łódź, 90-419 Łódź, Poland; robert.irzmanski@umed.lodz.pl

10 College of Rehabilitation, 01-234 Warsaw, Poland

* Correspondence: epiotrowicz@ikard.pl; Tel.: +48-22-3434664

\begin{abstract}
Background Adherence to treatment guidelines in heart failure (HF) patients is of major prognostic importance, but thorough implementation of guidelines in routine care remains insufficient. Introducing hybrid comprehensive telerehabilitation (HCTR) consisting of telecare, telerehabilitation, and remote monitoring of implantable devices might be an option to improve adherence to recommendation and can affect the prognosis. The purpose is to investigate the association of adherence to HCTR with mortality and hospitalization. (2) Methods This analysis formed part of TELEREH-HF multi-center, randomized trial that enrolled 850HF patients (NYHA I-III;LVEF $\leq 40 \%$ ). Patients were randomized 1:1 to 9-week HCTR (1 week in hospital and 8 weeks at home) plus usual care or usual care only and followed-up for 14 to 26 months. This analysis focuses on the HCTR group. Adherent patients were those who adhered both to the number of training sessions prescribed and to the duration of the prescribed cycle by at least $80 \%$; non-adherent patients were those who adhered $<20 \%$ to the prescribed number of training sessions and their duration. The remaining patients were classified as partially adherent. (3) Results There were $350(88.4 \%)$ adherent patients, $39(9.8 \%)$ partially adherent patients, and $7(1.8 \%)$ non-adherent patients. There were 46 deaths during follow-up. Non-adherence or partial adherence was associated with higher risk of cardiovascular $(\mathrm{CV})$ mortality (hazard ratio $(\mathrm{HR})=2.62, p=0.021$ ); all-cause mortality or HF hospitalization ( $\mathrm{HR}=1.71, p=0.038)$; CV mortality or HF hospitalization ( $\mathrm{HR}=1.89$, $p=0.014)$. (4) Conclusions The adherence to HCTR was high. Adherence to HCTR was associated with improved prognosis for CV mortality and the reduction in the combined outcome of CV mortality or HF hospitalization.
\end{abstract}

Keywords: telerehabilitation; adherence; heart failure 


\section{Introduction}

Heart failure (HF) can be effectively prevented and treated. There is a need to implement the knowledge acquired through large randomized clinical trials, included in the procedures standards, into everyday practice.

Adherence to treatment recommendations in HF patients is of major prognostic importance; however, thorough implementation of guidelines in routine care remains insufficient $[1,2]$.

In the current European and American guidelines for the management of HF, cardiac rehabilitation is a class 1 recommendation, level of evidence A [3,4]. Moreover, it is recommended to create and develop a multidisciplinary management program for HF patients. It should be done by incorporating both clinic-based and home-based strategies combined with patient engagement and self-evaluations [4-7].

Despite beneficial effects in improvements in functional capacity, quality of life, outcomes, cost-effectiveness, and strong recommendations, cardiac rehabilitation remains underused [1,5]. According to the recent EUROASPIRE V registry, less than half of patients $(46 \%)$ were advised to participate in a cardiac rehabilitation program, and $69 \%$ of those advised attended less than half of the sessions [8].

There may be several factors for poor adherence to cardiac rehabilitation [9]. Starting from the lack of resources and logistical problems (e.g., transportations issues, a lack of caregivers) and ending with patient-related reasons such as disability, helplessness, and psychological problems (e.g., the low motivation of the patients themselves, depression, anxiety) [1]. Despite the progress in pharmacological and non-pharmacological treatment of HF, the effects achieved are not always optimal. An important factor determining results after the treatment or the introduction of a new therapeutic procedure is patients adherence, which can affect their prognosis [10-12]. Therefore, both in the assessment of pharmacological treatment as well as in the evaluation of new procedures, it is advisable to evaluate them also in terms of their adherence.

Little is known about adherence to home-based remote supervised exercise training. To date, only a few papers assessed short-term adherence to telerehabilitation programs in HF patients. There are no published data that evaluate both the short-term adherence to telerehabilitation and its impact on long-term prognosis (when the intervention was completed) in HF patients depending on their good or poor adherence $[13,14]$.

The development of new telemedicine technologies made it possible to introduce a program of telerehabilitation that might be an option to overcome barriers hindering the implementation of cardiac rehabilitation in everyday clinical practice [1,6,7,9-12,15].

It is worth emphasizing that the recent scientific statement from the International Society for Holter and Noninvasive Electrocardiology/Heart Rhythm Society/European Heart Rhythm Association/Asia Pacific Heart Rhythm Society indicates the hybrid cardiac telerehabilitation as a novel promising approach [11]. Moreover, joint expert opinion by the Polish Cardiac Society and the Polish Academy of Science considers the comprehensive hybrid cardiac telerehabilitation as a procedure equivalent to the conventional inpatient and/or outpatient rehabilitation (class I) [12].

Therefore, we aimed to investigate the association of adherence to hybrid comprehensive telerehabilitation (HCTR) with mortality and hospitalization in the long-term follow-up, i.e., 14-26 months after the intervention was completed based on data from Telerehabilitation in Heart Failure Patients TELEREH-HF Randomized Clinical Trial.

\section{Materials and Methods}

The design and main results of the TELEREH-HF study have been published elsewhere $[16,17]$. The TELEREH-HF trial was a randomized (1:1), multi-center (5 centers in Poland), prospective, open-label, parallel-group, controlled study (Clinical Trials.gov NCT 02523560) that compared HCTR plus usual care (UC) with UC alone in 850 clinically stable HF patients (New York Heart Association (NYHA) class I, II, or III) with left ventricular ejection fraction (LVEF) $\leq 40 \%$ after a hospitalization due to worsening HF within 6 months 
prior to randomization. The detailed TELEREH-HF inclusion and exclusion criteria were previously published elsewhere $[16,17]$.

This analysis regarding adherence to exercise training focuses on patients randomized to the HCTR arm.

The HCTR intervention was multidisciplinary and consisted of telecare, personalized home-based telerehabilitation, and remote monitoring of cardiovascular implantable electronic devices. The HCTR group patients underwent a 9-week HCTR program consisting of an initial stage (1 week) in hospital and a basic stage (8 weeks) of HCTR performed at home, five times weekly. The HCTR was initiated during an in-hospital stay (five educational training sessions), and later on, the patients had to continue the remotely supervised exercise training at home (forty training sessions) over eight additional weeks combined with a multi-parameter telemonitoring. Exercise training was planned according to the published recommendations for HF patients [15,18]. Patients underwent 3 training modalities: endurance aerobic training based on Nordic walking, respiratory muscle training, and light resistance and strength training (Supplementary Materials Table S1).

A medical team (physicians, physiotherapists, nurses, and psychologists) was responsible for conducting the training sessions and interactive collaboration with patients.

The equipment for telemonitoring consisted of a remote device for tele-ECG-monitoring and supervising exercise training (the telerehabilitation set), a mobile phone, and the IT platform in a monitoring center. An EHO mini device is adjusted to register fragments of ECG (electrocardiographic) recording from three precordial leads and to transmit the data via a mobile phone network to the monitoring center. This device has training sessions preprogrammed individually for each patient (defined exercise duration, breaks, timing of ECG recording). The moments of automatic ECG registration are preset and coordinated with the exercise training $[16,17]$.

The HCTR group patients, before each training session (performed at home), were contacted via mobile phone by the nurse from the monitoring center and answered a series of questions regarding present symptoms and confirmed if they were taking any prescribed medications. Then patients transmitted their resting ECG, blood pressure, and body mass data to the monitoring center. If no contraindications to exercise training were found, patients received consent to start their training session. The ECGs were automatically recorded during the training session and transmitted to the monitoring center. After each training session, all data were evaluated in the monitoring center, and the physiotherapist contacted the patients to assess the patients' subjective perceived exertion on the Borg scale. Based on the data sent by patients, consultants were able to make further decisions.

A detailed description of the equipment and the intervention, including telesupervised exercise training, has been published elsewhere [16,17].

The study was guided by good clinical practice, in accordance with the Declaration of Helsinki and the regulations applicable in Poland. The trial protocol was approved by the local ethics committee (IK-NP-0021-85/1402/13). Each patient provided written informed consent $[16,17]$.

All HCTR group patients underwent the following assessments at entry and after completing the 9-week program: clinical examinations (including NYHA class assessment), cardiopulmonary exercise test (CPET), and the assessment of the adherence to HCTR. Patients were followed during 14-26 months after the intervention was ended to collect data regarding mortality and hospitalization.

\subsection{Cardiopulmonary Exercise Test}

The symptom-limited CPET on a treadmill according to a ramp protocol [19] and ESC guidelines [20] was performed using a Schiller MTM-1500 med. Oxygen consumption $\left(\mathrm{VO}_{2}\right)$ was measured continuously using breath-by-breath analysis. The peak $\mathrm{VO}_{2}$ value was presented per kilogram of body mass per minute $(\mathrm{mL} / \mathrm{kg} / \mathrm{min})$. Maximal exercise was defined as the respiratory exchange ratio (RER) $\geq 1$ or maximum fatigue according to the Borg scale $[16,17]$. 


\subsection{Assessment of Physical Capacity Improvement}

Functional response for HCTR was assessed by changes, delta $(\Delta)$ in peak $\mathrm{VO}_{2}$ in $\mathrm{CPET}$ as a result of comparing peak $\mathrm{VO}_{2}$ from the beginning and the end of the program.

\subsection{Assessment of the Adherence to Hybrid Comprehensive Telerehabilitation}

Adherence during the 9-week HCTR was assessed based on the daily telephone contact with the monitoring center, which was required to obtain the necessary permission for the training (consent procedure) and based on evaluation of transmitted the ECG data following each training session (compliance to the exercise training) [16,17]. Adherent (good adherent) patients were those who adhered both to the number of training sessions prescribed and to the duration of the prescribed cycle by at least $80 \%$; non-adherent patients were those who adhered $<20 \%$ to the prescribed number of training sessions and their duration. The rest was classified as partially adherent $[1,16,17]$. No measurement of adherence occurred after the 9-week training period as no intervention was intended to occur [17].

\subsection{Statistical Analyses}

Continuous variables are expressed as mean \pm standard deviation (SD) or medians and IQRs. Qualitative variables are reported as count and percentage. Characteristics of patients who were adherent vs. those who were partially adherent or non-adherent were compared using the chi-square test of independence or Fisher's exact test (when the expected number of events in the cell is less than 5) for categorical variables and two independent samples t-test (normally distributed data) or Mann-Whitney test (non-normally distributed data) for continuous variables. Ordinal variable was compared using Cochran Mantel-Haenszel Modified Ridit Scores (Row Mean Scores' statistic). Continuous outcome (change in peak $\mathrm{VO}_{2}$ in CPET) was compared between groups using analysis of variance adjusted for atrial fibrillation, HF, and baseline level of the outcome measure. NYHA class will be analyzed as an ordinal variable using ordinal logistic regression, including terms of baseline NYHA class. A general linear model was applied (PROC GLM in SAS 9.4 software), in which the independent variables, apart from the main adherence effect, were: HF, atrial fibrillation, and covariance in the form of the baseline measurement. The dependent variable was the difference between the tested measurement after 9 weeks and the baseline measurement.

Kaplan-Meier plots were created to illustrate survival experience, and differences were evaluated by the log-rank test. All time-to-event outcomes were compared between groups using Cox proportional hazards regression. Hazard ratios and their corresponding $95 \% \mathrm{CI}$ adjusted for atrial fibrillation/futter and etiology of HF. All tests were two-sided, and a $p$-value $<0.05$ was considered statistically significant. All analyses were conducted using SAS software version 9.4.

\section{Results}

The study flow chart is shown in Supplementary Materials Figure S1. Of the 2333 patients screened, $836 \mathrm{did}$ not meet inclusion/exclusion criteria, and 647 refused to participate. Of the 850 patients randomized, 425 were assigned to HCTR and 425 to UC. This analysis focuses on patients randomized to the HCTR group. A total of 27 patients did not participate in HCTR program due to: technical difficulties with operating the telerehabilitation set (21), new onset of comorbidities (4), return to work (2) [17]. Finally, 398 patients started HCTR. Two deaths occurred during the 9-week HCTR intervention, one due to hemorrhagic stroke and one non-cardiovascular. Therefore, in the end 396 patients were included in the present analysis.

Neither death occurred during telemonitored training sessions nor directly after (up to $1 \mathrm{~h}$ ). We were able to ascertain mortality status and hospitalization in all HCTR group patients and hospitalization during 14-26 months of follow-up after the intervention was finished [17]. 
Of the 396 patients analyzed in terms of their adherence to the HCTR program, there were $350(88.4 \%)$ adherent patients, $39(9.8 \%)$ partially adherent patients, and $7(1.8 \%)$ non-adherent patients. The causes of non-adherence were as follows: four patients had technical difficulties due to the lack of cellular network reception at home, one patient suffered from a prolonged respiratory infection, one had an exacerbation of comorbidities, and one had personal problems.

It is worth mentioning that of the 39 partially adherent patients: 21 patients underwent $70-78 \%$ prescribed training sessions, 5 patients $60-65 \%$ prescribed training sessions, 3 patients $53-55 \%$ prescribed training sessions, and only 10 patients $23-45 \%$ prescribed training sessions.

The baseline clinical characteristics of the whole HCTR group and of adherence subgroup vs. partially and non-adherence subgroup are presented in Table 1.

Table 1. Baseline characteristics of the hybrid comprehensive telerehabilitation group and comparison of baseline characteristics by degree of patients' adherence to hybrid comprehensive telerehabilitation.

\begin{tabular}{|c|c|c|c|c|}
\hline & $\begin{array}{l}\text { Hybrid Comprehensive } \\
\text { Telerehabilitation Group } \\
\qquad(\mathrm{n}=396)\end{array}$ & $\begin{array}{c}\text { Adherent Patients } \\
\text { Group } \\
(\mathrm{n}=350)\end{array}$ & $\begin{array}{l}\text { Partially Adherent and } \\
\text { Non-Adherent Patients Group } \\
(\mathrm{n}=46)\end{array}$ & $p$ \\
\hline Males, n (\%) & $354(89.4)$ & $313(89.4 \%)$ & $41(89.1 \%)$ & 1.00 \\
\hline Age (years), mean \pm SD & $62.2 \pm 10.7$ & $62.3 \pm 10.4$ & $61.2 \pm 13.1$ & 0.594 \\
\hline $\begin{array}{l}\text { Left ventricular ejection fraction } \\
\qquad(\%), \text { mean } \pm \mathrm{SD}\end{array}$ & $30.8 \pm 6.9$ & $31.0 \pm 6.8$ & $29.7 \pm 7.1$ & 0.222 \\
\hline $\begin{array}{c}\text { Atrial fibrillation or atrial flutter, } \\
\mathrm{n}(\%)\end{array}$ & 75 (18.9) & $61(17.4)$ & $14(30.4)$ & 0.034 \\
\hline $\begin{array}{c}\text { Body mass index }\left(\mathrm{kg} / \mathrm{m}^{2}\right), \text { mean } \\
\pm \mathrm{SD}\end{array}$ & $28.9 \pm 5.1$ & $28.7 \pm 5.0$ & $29.9 \pm 5.9$ & 0.136 \\
\hline \multicolumn{5}{|c|}{ Etiology of heart failure, n (\%) } \\
\hline Ischemic & $258(65.1)$ & $234(66.7)$ & $24(52.2)$ & \multirow{2}{*}{0.049} \\
\hline Non-ischemic & $138(34.9)$ & $116(33.1)$ & $22(47.8)$ & \\
\hline \multicolumn{5}{|c|}{ Past medical history, $\mathrm{n}(\%)$} \\
\hline Myocardial infarction & $231(58.3)$ & $208(59.4)$ & $23(50.0)$ & 0.223 \\
\hline Angioplasty & $187(47.2)$ & $171(48.9)$ & $16(37.8)$ & 0.072 \\
\hline Coronary artery bypass grafting & $59(14.9)$ & $52(14.9)$ & $7(15.2)$ & 0.949 \\
\hline Valve surgery & $32(8.1)$ & $28(8.0)$ & $4(8.7)$ & 0.777 \\
\hline Hypertension & $234(59.1)$ & $209(59.7)$ & $25(54.3)$ & 0.486 \\
\hline Stroke & $22(5.6)$ & $19(5.4)$ & $3(6.5)$ & 0.731 \\
\hline Diabetes & $133(33.6)$ & $121(34.6)$ & $12(26.1)$ & 0.252 \\
\hline Chronic kidney disease & $73(18.4)$ & $61(17.4)$ & $12(26.1)$ & 0.154 \\
\hline Depression BDI-II > 13 & $84 / 389(21.6)$ & $71(20.7)$ & $13(28.3)$ & 0.242 \\
\hline SF-36 overall (score) mean \pm SD & $90.1 \pm 12.4$ & $90.3 \pm 12.4$ & $87.7 \pm 11.3$ & 0.178 \\
\hline \multicolumn{5}{|c|}{ Functional status, n (\%) } \\
\hline NYHA I & $52(13.1)$ & $45(12.9)$ & $7(15.2)$ & \multirow{3}{*}{0.318} \\
\hline NYHA II & $277(69.9)$ & $249(71.1)$ & $28(60.9)$ & \\
\hline NYHA III & $67(16.9)$ & $56(16.0)$ & $11(23.9)$ & \\
\hline \multicolumn{5}{|l|}{ Parameters } \\
\hline NT-proBNP Medians [Q1-Q3] & $867.5[362.0-1997.0]$ & 859.5 [356-1935] & $1139.5[373.0-3030]$ & 0.185 \\
\hline $\begin{array}{l}\text { Peak oxygen consumption } \mathrm{pVO}_{2} \\
(\mathrm{~mL} / \mathrm{kg} / \mathrm{min}) \text { mean } \mathrm{SD}\end{array}$ & $17.0 \pm 5.6$ & $17.2 \pm 5.6$ & $15.5 \pm 5.5$ & 0.066 \\
\hline
\end{tabular}


Table 1. Cont.

\begin{tabular}{|c|c|c|c|c|}
\hline & $\begin{array}{l}\text { Hybrid Comprehensive } \\
\text { Telerehabilitation Group } \\
\qquad(\mathrm{n}=396)\end{array}$ & $\begin{array}{l}\text { Adherent Patients } \\
\text { Group } \\
(\mathrm{n}=350)\end{array}$ & $\begin{array}{l}\text { Partially Adherent and } \\
\text { Non-Adherent Patients Group } \\
(\mathrm{n}=46)\end{array}$ & $p$ \\
\hline \multicolumn{5}{|c|}{ Treatment, $\mathrm{n}(\%)$} \\
\hline Beta-blocker & $380(96.0)$ & $335(95.7)$ & $45(97.8)$ & 0.706 \\
\hline ACEI/ARB & $369(93.2)$ & $329(94.0)$ & $40(87.0)$ & 0.110 \\
\hline Digoxin & $51(12.9)$ & $44(12.6)$ & $7(15.2)$ & 0.614 \\
\hline Loop diuretics & $292(73.7)$ & $257(73.4)$ & $35(76.1)$ & 0.700 \\
\hline Spironolactone/eplerenone & $328(82.8)$ & $290(82.9)$ & $38(82.6)$ & 0.966 \\
\hline Aspirin/clopidogrel & $222(56.1)$ & $205(58.6)$ & $17(37.0)$ & 0.005 \\
\hline Anticoagulants & $117(29.5)$ & $104(29.7)$ & $13(28.3)$ & 0.839 \\
\hline NOAC & $65(16.4)$ & $52(14.9)$ & $13(28.3)$ & 0.021 \\
\hline Statins & $321(81.1)$ & $292(83.4)$ & $29(63.0)$ & $<0.001$ \\
\hline CIEDs & $314(79.3)$ & $275(78.6)$ & $39(84.8)$ & 0.328 \\
\hline ICD & $193(61.5)$ & $170(61.8)$ & $23(59.0)$ & 0.689 \\
\hline
\end{tabular}

SD, standard deviation; BDI-II, Beck Depression Inventory II; SF-36, Medical Outcome Survey Short Form 36; NYHA, New York Heart Association class; NT-proBNP, N-terminal prohormone of brain natriuretic peptide; ACEI, angiotensin-converting enzyme inhibitors; ARB, angiotensin receptor blockers; NOAC, non-vitamin $\mathrm{K}$ antagonist oral anticoagulants; CIEDs, cardiovascular implantable electronic devices; ICD, implantable cardioverter-defibrillator.

The groups were comparable in terms of demographic data, baseline clinical parameters, and pharmacotherapy except for the following parameters: presence of atrial fibrillation/flutter, etiology of $\mathrm{HF}$, and number of patients treated with antiplatelet drugs (aspirin/clopidogrel), non-vitamin $\mathrm{K}$ antagonist oral anticoagulants and statins.

\subsection{Functional Outcomes after 9 Weeks \\ 3.1.1. NYHA Class}

There was a significant change in the distribution of NYHA class from baseline to week 9. In between-group analysis (adherent patients vs. partially and non-adherent patients) the change in the distribution of NYHA class defined as: improvement, no change, deterioration were, respectively: $82(23.4 \%)$ vs. $4(8.7 \%) ; 246(70.3 \%)$ vs. $36(78,3 \%) ; 22(6.3 \%)$ vs. $6(13,0 \%) ; p=0.029$.

There was a significant improvement in NYHA class in the adherent patients versus partially and non-adherent patients (ordinal logistic regression including terms of baseline NYHA class, effect adherence: $p=0.006$ ). The details are presented in Table 2 .

Table 2. Change in distribution of NYHA class from baseline to week 9 comparison by degree of patients' adherence to hybrid comprehensive telerehabilitation.

\begin{tabular}{ccccc}
\hline & \multicolumn{2}{c}{ Adherent Patient Group } & \multicolumn{2}{c}{$\begin{array}{c}\text { Partially Adherent and } \\
\text { Non-Adherent Patients Group }\end{array}$} \\
\hline NYHA Class & Baseline & 9th Week & Baseline & 9th Week \\
\hline I & $45(12.9 \%)$ & $92(26.3 \%)$ & $7(15.2 \%)$ & $7(15.2 \%)$ \\
\hline II & $249(71.1 \%)$ & $215(61.4 \%)$ & $28(60.9 \%)$ & $26(56.5 \%)$ \\
\hline III & $56(16.0 \%)$ & $43(12.3 \%)$ & $11(23.9 \%)$ & $13(28.3 \%)$ \\
\hline
\end{tabular}

NYHA—New York Heart Association; between-groups analysis: baseline: $p=0.318$; 9th week: $p=0.009$.

\subsubsection{Functional Capacity}

After adjustment for differences in the baseline characteristics, there was a significant improvement in comparison to the baseline value in functional capacity assessed by peak $\mathrm{VO}_{2}$ only in the adherent patients: $\Delta$ peak $\mathrm{VO}_{2} 1.06 \mathrm{~mL} / \mathrm{kg} / \mathrm{min}(95 \% \mathrm{CI}: 0.72$, 
$1.40 \mathrm{~mL} / \mathrm{kg} / \mathrm{min})$. In the partially and non-adherent patients, this favorable effect was not observed $\Delta$ peak $\mathrm{VO}_{2} 0.95 \mathrm{~mL} / \mathrm{kg} / \mathrm{min}(95 \% \mathrm{CI}:-0.13,2.04 \mathrm{~mL} / \mathrm{kg} / \mathrm{min})$. Although the results were statistically significant, due to the fact that the partially and non-adherent group was small, this could possibly be considered a trend.

Yet, between-group analysis showed that there were no statistically significant differences between the groups regarding the improvement $(\Delta)$ in peak $\mathrm{VO}_{2}(p=0.855)$.

3.2. Impact of Patients' Adherence to HCTR on Long-Term Prognosis during 14-26 Months after the Intervention Was Completed

There were 46 deaths during the 14-26 months follow-up in the HCTR arm with mortality rates at 24 months $11.6 \%$. Non-adherence or partially adherence was associated with statistically significantly higher risk of cardiovascular $(\mathrm{CV})$ mortality (hazard ratio $(\mathrm{HR})=2.62 ; 95 \% \mathrm{CI}$ : (1.12-6.13); $p=0.021)$; composite endpoints combining: all-cause mortality or HF hospitalization ( $\mathrm{HR}=1.71 ; 95 \% \mathrm{CI}:(1.02-2.86) ; p=0.038)$, and CV mortality or HF hospitalization ( $\mathrm{HR}=1.89 ; 95 \% \mathrm{CI}$ : $(1.13-3.16) ; p=0.014)$. This association in terms of all-cause mortality or HF hospitalization and CV mortality or HF hospitalization remained after controlling for adjustment variables (HR $=1.79 ; 95 \%$ CI: $(1.06-3.04) ; p=0.030)$, $(\mathrm{HR}=1.99 ; 95 \% \mathrm{CI}:(1.17-3.39) ; p=0.012)$ respectively Table 3, Figures $1-3$.

Table 3. Time-to-event outcomes from randomization through end of follow-up in group receiving hybrid comprehensive telerehabilitation by the degree of patients' adherence to intervention.

\begin{tabular}{|c|c|c|c|c|c|c|c|c|}
\hline \multirow[t]{2}{*}{ Outcome } & \multicolumn{2}{|c|}{$\begin{array}{l}\text { Adherent Patients } \\
\text { Group N }=350\end{array}$} & \multicolumn{2}{|c|}{$\begin{array}{c}\text { Partially Adherent and } \\
\text { Non-Adherent Patients } \\
\text { Group N }=46\end{array}$} & \multirow[t]{2}{*}{$\begin{array}{l}\text { Hazard Ratio 95\% } \\
\text { Wald CL Partially } \\
\text { Adherent or } \\
\text { Non-Adherent vs. } \\
\text { Adherent }\end{array}$} & \multirow[t]{2}{*}{$p$-Value } & \multirow[t]{2}{*}{$\begin{array}{c}\text { Hazard Ratio * } \\
\text { 95\% Wald CL } \\
\text { Partially } \\
\text { Adherent or } \\
\text { Non-Adherent vs. } \\
\text { Adherent }\end{array}$} & \multirow[t]{2}{*}{$p$-Value } \\
\hline & N (\%) & $\begin{array}{c}\text { Event } \\
\text { Rate at } 26 \\
\text { Months }\end{array}$ & N (\%) & $\begin{array}{c}\text { Event Rate } \\
\text { at } 26 \\
\text { Months }\end{array}$ & & & & \\
\hline All-cause mortality & $38(10.9)$ & 10.5 & $8(17.4 \%)$ & 17.4 & $1.79(0.83-3.85)$ & 0.135 & $1.56(0.71-3.43)$ & 0.267 \\
\hline $\begin{array}{l}\text { Cardiovascular } \\
\text { mortality }\end{array}$ & $23(6.6 \%)$ & 6.3 & $7(15.6 \%)$ & 15.2 & $2.62(1.12-6.13)$ & 0.021 & $2.07(0.85-5.03)$ & 0.108 \\
\hline $\begin{array}{c}\text { All-cause } \\
\text { hospitalization }\end{array}$ & $201(57.4)$ & 58.3 & $19(41.3 \%)$ & 47.9 & $0.99(0.62-1.58)$ & 0.963 & $0.94(0.58-1.51)$ & 0.784 \\
\hline $\begin{array}{l}\text { Cardiovascular } \\
\text { hospitalization }\end{array}$ & $126(36.0)$ & 38.0 & $11(23.9 \%)$ & 28.1 & $0.84(0.45-1.55)$ & 0.570 & $0.81(0.43-1.51)$ & 0.508 \\
\hline $\begin{array}{c}\text { Heart failure } \\
\text { hospitalization }\end{array}$ & $86(24.6)$ & 25.7 & $13(28.3 \%)$ & 33.8 & $1.60(0.89-2.86)$ & 0.116 & $1.65(0.91-3.01)$ & 0.108 \\
\hline $\begin{array}{l}\text { All-cause mortality } \\
\text { or all-cause } \\
\text { hospitalization }\end{array}$ & $208(59.4)$ & 59.7 & $23(50.0 \%)$ & 55.3 & $1.16(0.75-1.78)$ & 0.506 & 1.09 (0.71-1.69) & 0.694 \\
\hline $\begin{array}{l}\text { All-cause mortality } \\
\text { or cardiovascular } \\
\text { hospitalization }\end{array}$ & $151(43.1)$ & 43.9 & $17(37.0 \%)$ & 40.9 & $1.08(0.65-1.78)$ & 0.761 & $1.03(0.62-1.72)$ & 0.904 \\
\hline $\begin{array}{l}\text { All-cause mortality } \\
\text { or heart failure } \\
\text { hospitalization }\end{array}$ & $105(30.0)$ & 30.6 & $17(37.0 \%)$ & 41.2 & $1.71(1.02-2.86)$ & 0.038 & $1.79(1.06-3.04)$ & 0.030 \\
\hline $\begin{array}{c}\text { Cardiovascular } \\
\text { mortality or heart } \\
\text { failure } \\
\text { hospitalization }\end{array}$ & $95(27.1)$ & 28.1 & $17(37.0 \%)$ & 41.2 & $1.89(1.13-3.16)$ & 0.014 & $1.99(1.17-3.39)$ & 0.012 \\
\hline
\end{tabular}

* Adjusted for atrial fibrillation/flutter, an etiology of heart failure, baseline New York Heart Association class, systolic blood pressure, peak oxygen consumption, glomerular filtration rate, N-terminal prohormone of brain natriuretic peptide. 


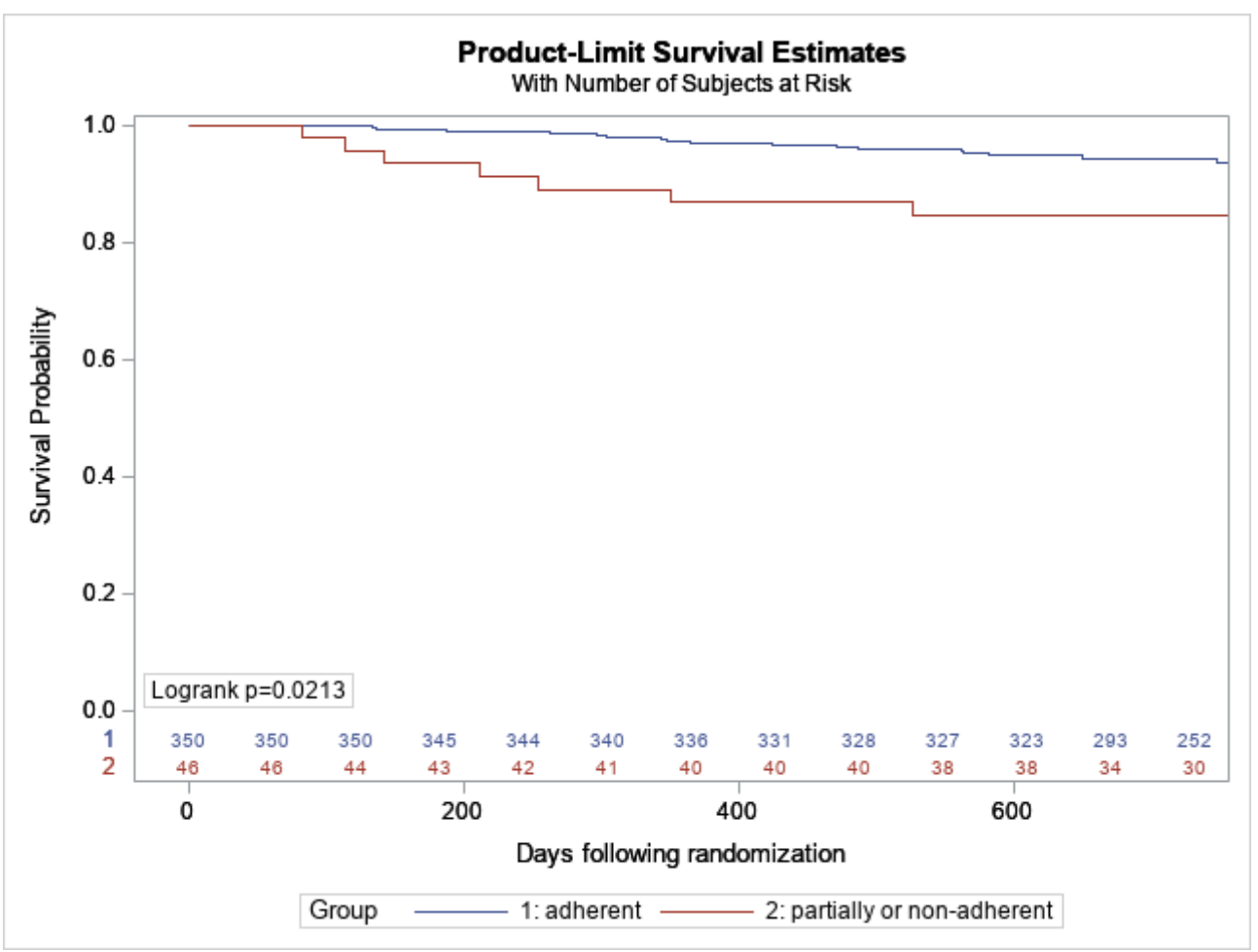

Figure 1. Kaplan-Meier probability of cardiovascular mortality-free survival in adherent patients vs. partially and non-adherent patients.

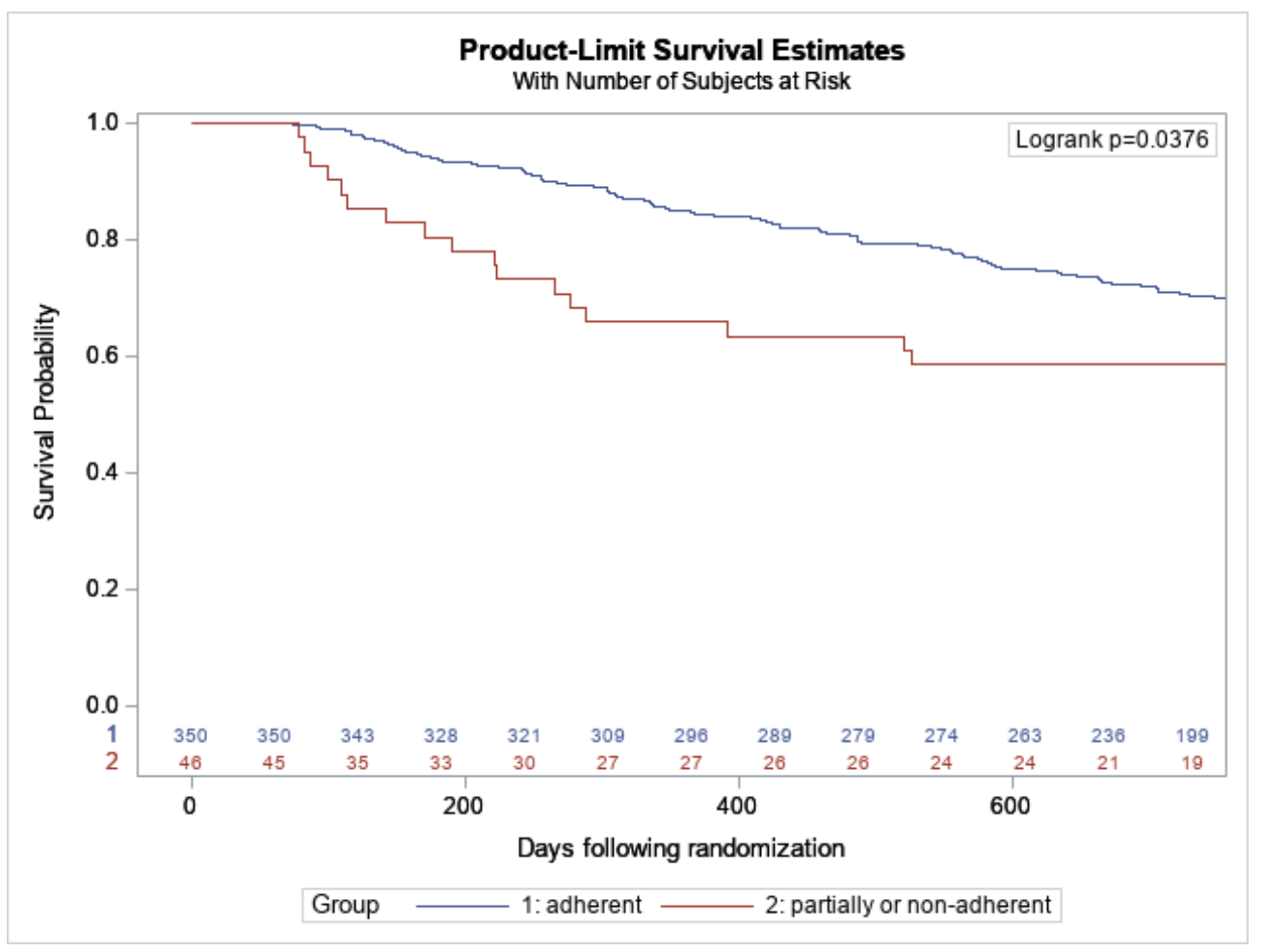

Figure 2. Kaplan-Meier probability of all-cause mortality or heart failure hospitalization in adherent patients vs. partially and non-adherent patients. 


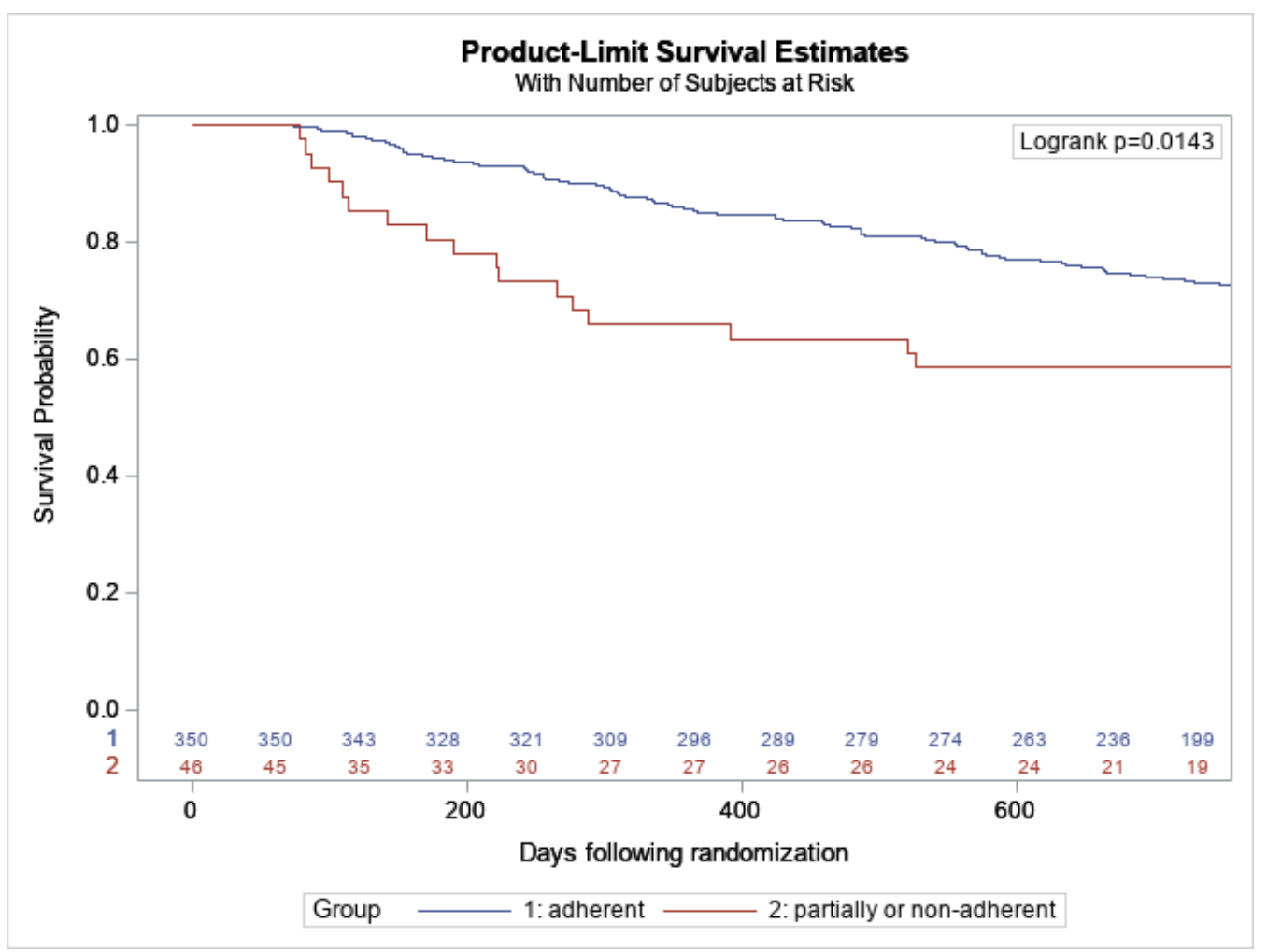

Figure 3. Kaplan-Meier probability of cardiovascular mortality or heart failure hospitalization in adherent patients vs. partially and non-adherent patients.

There were no statistically significant differences in all-cause mortality, all-cause hospitalization, CV hospitalizations, HF hospitalizations, or composite endpoints combining: all-cause mortality or all-cause hospitalization, and all-cause mortality or CV hospitalization Table 3.

\section{Discussion}

The significant finding of the present subanalysis of our multicentre randomized controlled trial is that high adherence to the 9-week hybrid, comprehensive, cardiac telerehabilitation results in a significant improvement of NYHA class, peak $\mathrm{VO}_{2}$, and it translates into a reduction in CV mortality and the composite endpoint of CV mortality or HF hospitalization in the long-term follow-up when the intervention was completed. In contrast to the partially and non-adherent group of patients, these favorable results were not observed. Additionally, our study showed that there are premises to believe that the 9-week intervention was sufficient to achieve high adherence in over $88 \%$ of patients who underwent HCTR, which might have resulted from both short-term improvement of physical capacity and long-term improvement of the prognosis. Moreover, these findings indirectly indicate that patients after the end of the intervention were able to implement healthy habits into everyday routine. It concerns patients' understanding of the necessity to follow both regular exercise training and daily pharmacological treatment as well as appropriate diet and promotion of mental health. The main analysis of the entire population of TELEREH-HF RCT demonstrated that a 9-week HCTR significantly improves the physical capacity and quality of life of HF patients in contrast with the usual care [17,21]. Yet, it had no significant impact on mortality and rehospitalization rates in a long-term follow-up [17]. Only the subanalysis with the division into adherent patients versus partially and non-adherent patients proved that only adherent to HCTR patients achieved benefits in long-term follow-up in terms of prognosis and reducing hospitalization rates. It is in line with the World Health Organization statement that "Increasing the effectiveness of adherence intervention may 
have a far greater impact on the health of the population than any improvement in specific medical treatments" [22].

There are only a few studies that were published that investigate the adherence to home-based telemonitored cardiac rehabilitation programs in HF patients. A single-center study randomly assigned $152 \mathrm{HF}$ patients to an 8-week new model of home-based telemonitored rehabilitation or an outpatient-based standard rehabilitation. In line with our results, the adherence to telerehabilitation was high, and all patients completed cardiac telerehabilitation program in contrast to standard rehabilitation, where the drop-out was $20 \%$ [13]. In another single-center trial, $111 \mathrm{HF}$ patients were randomized in ratio 2:1 to a home-based telemonitored an 8-week Nordic walking training five times weekly or usual care. This study reported that $94.7 \%$ of the patients were adherent to telerehabilitation, only $5.3 \%$ of patients were partially adherent, and there were no non-adherent patients [14]. These results are consistent with our findings in terms of high adherence to the intervention. However, in our TELEREH-HF study, we noted $1.8 \%$ of non-adherent patients. Moreover, the results of published studies assessing the short-term effectiveness of telerehabilitation programs for HF patients are consistent and clearly indicated an improvement in both physical capacity and quality of life, which is a consequence of good adherence. Unfortunately, these two single-center studies did not assess the long-term impact of telerehabilitation on prognosis, unlike our multi-center trial $[14,15,17]$. However, the type of telemonitoring and the assessment of adherence were identical to those in our study $[13,14,16,17]$.

A small, non-randomized study by Smart et al. (2005) assessed $30 \mathrm{HF}$ patients who underwent 4 months of hospital-based exercise training followed by 8 months of homebased telemonitoring with heart rate monitors (downloaded bimonthly), exercise diaries and weekly telephone contact, cardiac rehabilitation program. Only adherent patients $(50 \%)$ showed persistent improvement of physical capacity and quality of life at 12 months [23]. In our study, the multidisciplinary telemedicine intervention was completed after 9 weeks and was not extended in the long-term follow-up. Nevertheless, it has proved effective in improving the prognosis in HF patients in long-term follow-up [17].

Hwang et al. (2017) randomized 53 HF patients to 12 weeks (twice weekly) home-based telerehabilitation or standard rehabilitation group with follow-up of the next 12 weeks. The authors found that the 6 min walk test distance and quality of life changes after both models of rehabilitation improved significantly. Nevertheless, this improvement did not maintenance during the next 12 weeks of unsupervised exercise phase at follow-up. Regarding adherence to exercise training, significantly higher attendance rates were observed in the home-based telerehabilitation group. There were $71 \%$ vs. $30 \%$ adherent patients, $29 \%$ vs. $63 \%$ partly adherent patients, $0 \%$ vs. $7 \%$ non-adherent patients in the telerehabilitation group in comparison to the standard rehabilitation group, respectively [24]. These adherence results are in line with those obtained in our study. However, we did not assess physical capacity in long-term follow-up.

In the Telerehab III trial by Frederix et al. (2015), 140 patients were randomized to an Internet-based comprehensive telerehabilitation program in addition to conventional central-based rehabilitation or conventional central-based rehabilitation alone. This study demonstrated that a 24-week tailored telerehabilitation initiated 6 weeks after the start of conventional rehabilitation led to a bigger physical capacity improvement, measured by peak $\mathrm{VO}_{2}$. The number of days lost due to cardiovascular rehospitalizations in the telerehabilitation group was significantly lower than in the standard rehabilitation group in one-year follow-up after study termination [25]. Our study showed a reduction in HF rehospitalization rates only in the adherent group patients. It is worth noting that the population of the Telerehab III study differed from that randomized to our study, while in the Telerehab III trial, only 3\% of patients had HF with reduced ejection fraction [25]. Additionally, the authors did not evaluate adherence in detail.

In the context of HF patients' adherence to rehabilitation programs, it is worth citing the HF-ACTION study, bearing in mind that the methodology, the intervention, and the follow-up protocol are completely different from the TELEREH-HF trial. In the HF- 
ACTION trial, 2331 HF patients were randomized either to an aerobic exercise training group or a usual care group in order to determine whether the intervention is able to improve physical capacity and quality of life and to reduce all-cause mortality or all-cause hospitalization. The results showed that exercise training led only to a non-significant $7 \%$ reduction in all-cause mortality or all-cause hospitalization after a median follow-up of 30 months. Although after adjustment for prespecified prognostic factors, the composite primary endpoint was significantly reduced by $11 \%$ [26]. Contrary to our results, there was only $26 \%$ full adherent to exercise training patients, $15 \%$ partial adherent patients, and $59 \%$ poor adherent patients [26]. However, the intervention in the TELEREH-HF trial was much shorter, and exercise training at home was remotely monitored. Similarly, to our study, in the HF-ACTION trial, there was no association between exercise adherence and the primary outcome of all-cause death or hospitalization. However, compared with full adherence, poor adherence was associated with a higher risk of cardiovascular death or HF hospitalization $[25,26]$. These findings were confirmed by our study.

The studies presented above differ in terms of monitoring methodology, intervention time, follow-up length, and adherence assessment, therefore it is difficult to compare them; only Hwang et al. (2017) assessed adherence based on the same methodology as in our article [23-26].

Adherence to long-term therapy and following healthy behavior is of great importance. Unfortunately, adherence to long-term treatment, especially in chronic diseases, is still poor. Insufficient adherence to long-term therapies leads to poor outcomes and affects health care costs. Therefore, the search for procedures that support patient collaboration is crucial [1,2,27-29]. New telemedicine technologies along with artificial intelligence can contribute to the improvement of patients' adherence. Therefore, it is extremely important to evaluate them before introducing them to everyday clinical practice, which we did in our subanalysis. Our study showed that there is no doubt that the daily contact of the patient with the medical team the analysis of the transmitted data improves physical capacity and well-being, which translates into improved prognosis in long-term follow-up even after the end of the intervention.

\section{Limitation}

The current subanalysis has some limitations. Firstly, we assessed adherence to comprehensive telerehabilitation and its impact on prognosis only in the HCTR group patients. More information would be provided by comparing the adherence between the HCTR and UC groups. However, we did not collect such data, especially since only $12 \%$ of UC group patients participated in cardiac rehabilitation programs.

Secondly, we did not gather data on maintaining patients' adherence to medical recommendations, as well as data regarding physical capacity and repeating any training programs in the long-term follow-up after the 9-week intervention period. Thirdly, in this subanalysis, women constituted only $11 \%$ of HCTR group patients; therefore, extrapolating those results to the female population may not be reliable. Additionally, we did not collect data on the socioeconomic status of patients, which would provide more information on the factors favoring full adherence. Finally, the low numbers of partially or non-adherent patients are very satisfactory, but on the other hand, this may have had an impact on the statistical analyses, and this way could have affected the results.

\section{Conclusions}

The heart failure patients' adherence to the 9-week hybrid comprehensive telerehabilitation was very high. Good adherence to the 9-week hybrid comprehensive telerehabilitation was associated with improved prognosis for cardiovascular mortality and the reduction in the combined outcome of cardiovascular mortality or heart failure hospitalization. 
Supplementary Materials: The following supporting information can be downloaded at: https: / / www.mdpi.com/article/10.3390/app12052595/s1, Figure S1: Patient Flow in the Study, Table S1: Exercise training model TELEREH-HF RCT.

Author Contributions: E.P. and R.P. contributed to the conception or design of the work. All contributed to the acquisition, analysis, or interpretation of data for the work. E.P., R.P. and I.K. drafted the manuscript. All critically revised the manuscript, gave final approval, and agreed to be accountable for all aspects of work, ensuring integrity and accuracy. All authors have read and agreed to the published version of the manuscript.

Funding: This research was funded by the National Center for Research and Development, Warsaw, Poland (grant number STRATEGMED1/233547/13/NCBR/2015).

Institutional Review Board Statement: The study was conducted in accordance with the Declaration of Helsinki and approved by the Ethics Committee of National Institute of Cardiology, Warsaw, Poland (IK-NP-0021-85/1402/13); 5 November 2013).

Informed Consent Statement: Informed consent was obtained from all subjects involved in the study.

Data Availability Statement: The datasets are available from the corresponding authors on reasonable requests.

Acknowledgments: The authors thank all the medical and technology TELEREH-HF team.

Conflicts of Interest: The authors were supported by National Centre for Research and Development, Warsaw, Poland.

\section{References}

1. Conraads, V.M.; Deaton, C.; Piotrowicz, E.; Santaularia, N.; Tierney, S.; Piepoli, M.F.; Pieske, B.; Schmid, J.P.; Dickstein, K.; Ponikowski, P.P.; et al. Adherence of heart failure patients to exercise: Barriers and possible solutions: A position statement of the Study Group on Exercise Training in Heart Failure of the Heart Failure Association of the European Society of Cardiology. Eur. J. Heart Fail. 2012, 14, 451-458. [CrossRef] [PubMed]

2. Deka, P.; Pozehl, B.; Williams, M.A.; Yates, B. Adherence to recommended exercise guidelines in patients with heart failure. Hear. Fail. Rev. 2016, 22, 41-53. [CrossRef] [PubMed]

3. McDonagh, T.A.; Metra, M.; Adamo, M.; Gardner, R.S.; Baumbach, A.; Böhm, M.; Burri, H.; Butler, J.; Čelutkienė, J.; Chioncel, O.; et al. 2021 ESC Guidelines for the diagnosis and treatment of acute and chronic heart failure. Eur. Heart J. 2021, 42, 3599-3726. [CrossRef]

4. Seferovic, P.M.; Ponikowski, P.; Anker, S.D.; Bauersachs, J.; Chioncel, O.; Cleland, J.G.; De Boer, R.A.; Drexel, H.; Ben Gal, T.; Hill, L.; et al. Clinical practice update on heart failure 2019: Pharmacotherapy, procedures, devices and patient management. An expert consensus meeting report of the Heart Failure Association of the European Society of Cardiology. Eur. J. Hear. Fail. 2019, 21, 1169-1186. [CrossRef]

5. Thomas, R.J.; Beatty, A.L.; Beckie, T.M.; Brewer, L.C.; Brown, T.M.; Forman, D.E.; Franklin, B.A.; Keteyian, S.J.; Kitzman, D.W.; Regensteiner, J.G.; et al. Home-Based Cardiac Rehabilitation. A Scientific Statement From the American Association of Cardiovascular and Pulmonary Rehabilitation the American Heart Association, and the American College of Cardiology. J. Am. Coll. Cardiol. 2019, 74, 133-153. [CrossRef] [PubMed]

6. Bozkurt, B.; Fonarow, G.C.; Goldberg, L.R.; Guglin, M.; Josephson, R.A.; Forman, D.E.; Lin, G.; Lindenfeld, J.; O’Connor, C.; Panjrath, G.; et al. Cardiac Rehabilitation for Patients With Heart Failure. JACC Expert Panel Perspective From the ACC Heart Failure and Transplant Section and Leadership Council, Reviewed by the Prevention Section Cardiac Rehabilitation Work Group. J. Am. Coll. Cardiol. 2021, 77, 1454-1469. [CrossRef] [PubMed]

7. Ambrosetti, M.; Abreu, A.; Corrà, U.; Davos, C.H.; Hansen, D.; Frederix, I.; Iliou, M.C.; Pedretti, R.F.; Schmid, J.P.; Vigorito, C.; et al. Secondary prevention through comprehensive cardiovascular rehabilitation: From knowledge to implementation. 2020 update. A position paper fromthe Secondary Prevention and Rehabilitation Section of the European Association of Preventive Cardiology. Eur. J. Prev. Cardiol. 2021, 28, 460-495. [CrossRef] [PubMed]

8. Kotseva, K.; De Backer, G.; De Bacquer, D.; Rydén, L.; Hoes, A.; Grobbee, D.; Maggioni, A.; Marques-Vidal, P.; Jennings, C.; Abreu, A.; et al. Lifestyle and impact on cardiovascular risk factor control in coronary patients across 27 countries: Results from the European Society of Cardiology ESC-EORP EUROASPIRE V registry. Eur. J. Prev. Cardiol. 2019, 26, 824-835. [CrossRef] [PubMed]

9. Winnige, P.; Filakova, K.; Hnatiak, J.; Dosbaba, F.; Bocek, O.; Pepera, G.; Papathanasiou, J.; Batalik, L.; Grace, S.L. Validity and Reliability of the Cardiac Rehabilitation Barriers Scale in the Czech Republic (CRBS-CZE): Determination of Key Barriers in East-Central Europe. Int. J. Environ. Res. Public Health 2021, 18, 13113. [CrossRef]

10. Piotrowicz, E.; Piepoli, M.F.; Jaarsma, T.; Lambrinou, E.; Coats, A.J.; Schmid, J.-P.; Corrà, U.; Agostoni, P.; Dickstein, K.; Seferović, P.M.; et al. Telerehabilitation in heart failure patients: The evidence and the pitfalls. Int. J. Cardiol. 2016, 220, 408-413. [CrossRef] 
11. Varma, N.; Cygankiewicz, I.; Turakhia, M.; Heidbuchel, H.; Hu, Y.; Chen, L.Y.; Couderc, J.; Cronin, E.M.; Estep, J.D.; Grieten, L.; et al. 2021 ISHNE/ HRS/ EHRA/ APHRS collaborative statement on mHealth in Arrhythmia Management: Digital Medical Tools for Heart Rhythm Professionals. Ann. Noninvasive Electrocardiol. 2021, 26, e12795. [CrossRef] [PubMed]

12. Piotrowicz, R.; Krzesiński, P.; Balsam, P.; Piotrowicz, E.; Kempa, M.; Lewicka, E.; Główczyńska, R.; Grabowski, M.; Kołtowski, Ł.; Peller, M.; et al. Telemedicine solutions in cardiology: A joint expert opinion by the Information Technology and Telemedicine Committee of the Polish Cardiac Society, the Section of Noninvasive Electrocardiology and Telemedicine of the Polish Cardiac Society, and the Clinical Research Committee of the Polish Academy of Sciences (short version, 2021). Kardiol. Pol. 2021, 79, 227-241. [CrossRef]

13. Piotrowicz, E.; Baranowski, R.; Bilinska, M.; Stepnowska, M.; Piotrowska, M.; Wójcik, A.; Korewicki, J.; Chojnowska, L.; Małek, Ł.A.; Klopotowski, M.; et al. A new model of home-based telemonitored cardiac rehabilitation in patients with heart failure: Effectiveness, quality of life, and adherence. Eur. J. Hear. Fail. 2010, 12, 164-171. [CrossRef] [PubMed]

14. Piotrowicz, E.; Zieliński, T.; Bodalski, R.; Rywik, T.; Dobraszkiewicz-Wasilewska, B.; Sobieszczańska-Małek, M.; Stepnowska, M.; Przybylski, A.; Browarek, A.; Szumowski, Ł.; et al. Home-based telemonitored Nordic walking training is well accepted, safe, effective and has high adherence among heart failure patients, including those with cardiovascular implantable electronic devices-A randomized controlled study. Eur. J. Prev. Cardiol. 2015, 22, 1368-1377. [CrossRef]

15. Piepoli, M.F.; Conraads, V.; Corrà, U.; Dickstein, K.; Francis, D.P.; Jaarsma, T.; Mcmurray, J.; Pieske, B.; Piotrowicz, E.; Schmid, J.-P.; et al. Exercise training in heart failure: From theory to practice. A consensus document of the Heart Failure Association and the European Association for Cardiovascular Prevention and Rehabilitation. Eur. J. Hear. Fail. 2011, 13, 347-357. [CrossRef]

16. Piotrowicz, E.; Piotrowicz, R.; Opolski, G.; Pencina, M.; Banach, M.; Zaręba, W. Hybrid comprehensive telerehabilitation in heart failure patients (TELEREH-HF): A randomized, multicenter, prospective, open-label, parallel group controlled trial—Study design and description of the intervention. Am. Hear. J. 2019, 217, 148-158. [CrossRef] [PubMed]

17. Piotrowicz, E.; Pencina, M.J.; Opolski, G.; Zaręba, W.; Banach, M.; Kowalik, I.; Orzechowski, P.; Szalewska, D.; Pluta, S.; Główczyńska, R.; et al. Effects of a 9-Week Hybrid Comprehensive Telerehabilitation Program on Long-term Outcomes in Patients With Heart Failure: The Telerehabilitation in Heart Failure Patients (TELEREH-HF) Randomized Clinical Trial. JAMA Cardiol. 2020, 5, 300-308. [CrossRef]

18. Batalik, L.; Pepera, G.; Papathanasiou, J.; Rutkowski, S.; Líška, D.; Batalikova, K.; Hartman, M.; Felšőci, M.; Dosbaba, F. Is the Training Intensity in Phase Two Cardiovascular Rehabilitation Different in Telehealth versus Outpatient Rehabilitation? J. Clin. Med. 2021, 10, 4069. [CrossRef] [PubMed]

19. Balady, G.J. Medical evaluation and exercise testing. In Guidelines for Cardiac Rehabilitation and Secondary Prevention Programs, 4th ed.; Williams, M.A., Ed.; Human Kinetics: Champaign, IL, USA, 2004; p. 79.

20. Piepoli, M.F.; Corrà, U.; Agostoni, P.G.; Belardinelli, R.; Cohen-Solal, A.; Hambrecht, R.; Vanhees, L. Task Force of the Italian Working Group on Cardiac Rehabilitation and Prevention (Gruppo Italiano di Cardiologia Riabilitativa e Prevenzione, GICR); Working Group on Cardiac Rehabilitation and Exercise Physiology of the European Society of Cardiology. Statement on cardiopulmonary exercise testing in chronic heart failure due to left ventricular dysfunction: Recommendations for performance and interpretation Part II: How to perform cardiopulmonary exercise testing in chronic heart failure. Eur. J. Cardiovasc. Prev. Rehabil. 2006, 13, 300-311. [CrossRef]

21. Piotrowicz, E.; Mierzyńska, A.; Banach, M.; Jaworska, I.; Pencina, M.; Kowalik, I.; Pluta, S.; Szalewska, D.; Opolski, G.; Zaręba, W.; et al. Quality of life in heart failure patients undergoing hybrid comprehensive telerehabilitation versus usual care-Results of the Telerehabilitation in Heart Failure Patients (TELEREH-HF) Randomized Clinical Trial. Arch. Med Sci. 2020, 17, 1599-1612. [CrossRef] [PubMed]

22. World Health Organization (WHO). Adherence to Long-Term Therapies: Evidence for Action; Sabete, E., Ed.; World Health Organization: Geneva, Switzerland, 2003. Available online: http://www.who.int/chp/knowledge/publications/adherence_introduction. pdf (accessed on 4 August 2017).

23. Smart, N.; Haluska, B.; Jeffriess, L.; Marwick, T.H. Predictors of sustained response to exercise training in patients with chronić heart failure: A telemonitoring study. Am. Heart J. 2005, 150, 1240-1247. [CrossRef] [PubMed]

24. Hwang, R.; Bruning, J.; Morris, N.R.; Mandrusiak, A.; Russell, T. Home-based telerehabilitation is not inferior to a centre-based program in patients with chronic heart failure: A randomised trial. J. Physiother. 2017, 63, 101-107. [CrossRef] [PubMed]

25. Frederix, I.; Hansen, D.; Coninx, K.; Vandervoort, P.; Vandijck, D.; Hens, N.; Van Craenenbroeck, E.; Van Driessche, N.; Dendale, P. Effect of comprehensive cardiac telerehabilitation on one-year cardiovascular rehospitalization rate, medical costs and quality of life: A cost-effectiveness analysis. Eur. J. Prev. Cardiol. 2016, 23, 674-682. [CrossRef]

26. O'Connor, C.M.; Whellan, D.J.; Lee, K.L.; Keteyian, S.J.; Cooper, L.S.; Ellis, S.J.; Leifer, E.S.; Kraus, W.E.; Kitzman, D.W.; Blumenthal, J.A.; et al. Efficacy and safety of exercise training in patients with chronic heart failure: HF-ACTION randomized controlled trial. JAMA 2009, 301, 1439-1450. [CrossRef] [PubMed]

27. Cooper, L.B.; Mentz, R.J.; Sun, J.L.; Schulte, P.J.; Fleg, J.L.; Cooper, L.S.; Piña, I.L.; Leifer, E.S.; Kraus, W.E.; Whellan, D.J.; et al. Psychosocial Factors, Exercise Adherence, and Outcomes in Heart Failure Patients Insights From Heart Failure: A Controlled Trial Investigating Outcomes of Exercise Training (HF-ACTION). Circ. Heart Fail. 2015, 8, 1044-1051. [CrossRef] [PubMed] 
28. Whellan, D.J. Long-Term Exercise Training and Adherence It Is Not Just Exercise. J. Am. Coll. Cardiol. 2012, 60, 1529-1530. [CrossRef]

29. Niewada, M.; Tabor, B.; Piotrowicz, E.; Piotrowicz, R.; Opolski, G.; Banach, M.; Jakubczyk, M. Cost-effectiveness of telerehabilitation in patients with heart failure in Poland: An analysis based on the results of Telerehabilitation in the Heart Failure Patients (TELEREH-HF) randomized clinical trial. Kardiol Pol. 2021, 79, 510-516. [CrossRef] 